\title{
Sensitivity analysis of SWAT model in the Yarra River catchment
}

\author{
$\underline{\text { S.K. Das }}^{\mathrm{a}}$, A.W.M. Ng ${ }^{\mathrm{a}}$ and B.J.C. Perera ${ }^{\mathrm{a}}$ \\ ${ }^{a}$ College of Engineering and Science, Victoria University, Melbourne 14428, Australia \\ Email: sushilkumar.das@live.vu.edu.au
}

\begin{abstract}
Catchment-scale hydrologic and diffuse source pollution models simulating a catchment are useful analysis tools to understand problems and find solutions through simulation of BMPs for particular catchment and agronomic settings. However, developing reliable catchment model and validating them on real-world catchment with monitored data is challenging. In this regard, model calibration and uncertainty analysis help to evaluate the ability of the model to sufficiently predict streamflow and constituent yields for specific applications. Complex physics-based distributed models contain many parameters that can complicate calibration process. In addition, the model when includes multi-variable at multi-site with multiobjective functions introduces more complexity to the calibration process. Over-parameterization is a wellknown problem in such distributed model. Sensitivity analysis methods reducing the number of parameters to be adjusted during calibration are important for simplifying the use of these models. The objective of this paper is to perform a sensitivity analysis for multiple variables (streamflow, sediment and nutrients) at three sites on a SWAT model developed in the agricultural part of the Yarra River catchment, Victoria (Australia) so that the model can be calibrated efficiently for water quality analysis purposes.
\end{abstract}

SWAT is a continuous physics-based distributed model that operates on a daily time-step. The SWAT model requires the following data types: digital elevation model (DEM), land use, soil, land use management, daily climate, streamflow and water quality data. Australian catchments are data-rich in terms of hydroclimatic data, but data-poor especially for water quality and land use management. For this study, all the data were collected from local organizations except DEM. Water quality and land use management data were most sparse. All input files for the model were organized and assembled following the guidelines of ArcSWAT interface of the SWAT 2005 version. The study area was delineated into 51 sub-catchments and 431 hydrological response units (HRU), which are unique combinations of land use, soil type and slope. The main methods used in modeling the hydrologic processes in SWAT were curve number method for runoff estimating, Penman-Monteith method for PET and Muskingum method for channel routing.

SWAT has an embedded automatic sensitivity, and calibration and uncertainty analysis tool. The sensitivity analysis method is a combination of Latin-Hypercube and One-factor-At-a-Time (LH-OAT) sampling that allows a global sensitivity analysis for a long list of parameters with only a limited number of model runs. SWAT has 26 streamflow, 6 sediment and 9 nutrient parameters. The LH-OAT sensitivity analysis was applied for streamflow (Q), Total Nitrogen (TN), Total Phosphorus (TP) and Total Suspended Solid (TSS) output variables at three sites in the study area for 1998-2008 periods.

The LH-OAT sensitivity analysis provides a simple and quick way to assess parameter sensitivity for multiple variables across the study area. The output variables found to be most sensitive to 15 hydrologic parameters, and 13 sediment and nutrients parameters in the SWAT model. The results show that the hydrologic parameters dominate the highest parameter ranks. The results also show that water quality variables are potentially capable of contributing to the identification of water quantity parameters within the SWAT model, and a single parameter is correlated to multiple variables. Moreover, there were clear differences in ranking of a parameter among the three sites. This result has evidenced how the parameter importance depends on land use, topography and soil types, meaning that a generalization within a catchment is limited. Hence, justify the importance of multi-site parameterization

Keywords: Sensitivity analysis, SWAT, Latin-Hypercube and One-factor-At-a-Time (LH-OAT) sampling, Yarra River catchment, Australia 


\section{INTRODUCTION}

Public concern regarding the degradation of water quality due to nonpoint sources and point sources has driven policy regulators to scrutinize land management practices and examine how water quality conditions can be improved. Agricultural practices are commonly regarded as being sources of water and soil contamination (Sharpley, 1995). Land application of fertilizer/manure provides nutrients and organic matter that enhance crop growth and can improve soil physical properties. However, when applied in excess, runoff from overlands can result in the impairment of nearby water resources. Phosphorus $(\mathrm{P})$ is a recognized contaminant that can cause adverse conditions in surface waters whereas nitrogen $(\mathrm{N})$ is more important in marine systems (Sims et al., 1998). Environmental regulation has expedited the necessity of agricultural producers to design and implement more environmentally suitable practices. There is a need to identify critical nutrient and their loss/transport potentials. Catchment water quality models can simulate multiple catchment management scenarios that can help environmental policy managers make decisions that could ultimately reduce $\mathrm{P}$ and $\mathrm{N}$ loss from agricultural lands (Green and van Griensven, 2008). Models are inexpensive tools that can identify optimum catchment management practice scenarios for pollutant transport reduction.

Catchment models that aim to describe water quality variables such as sediment fluxes, nutrients and other dissolved compounds that affect stream ecology need detailed rainfall-runoff process descriptions in time and space. Additionally, these models must account for a number of transformation processes. Therefore, continuous physics-based distributed models are better suited for the accurate simulation of spatial and temporal patterns in surface runoff, sediment, chemicals, and nutrients and their associated transport pathways (Borah and Bera, 2003). The increased complexity in such models is that they have more model parameters than simpler rainfall-runoff models. These parameters are involved with different processes of the catchment such as runoff, erosion, evaporation, groundwater and so on, and cannot be measured directly due to measurement limitations and scaling issues. These models also require significantly longer simulation times than equivalent rainfall runoff-models.

Developing reliable physics-based catchment models and validating them on real-world catchment with measured and monitored data is challenging. In this regard, model calibration and uncertainty analysis help to evaluate the ability of the model to sufficiently predict streamflow and constituent yields for specific applications (White and Chaubey, 2005). Complexity in the calibration and validation process increases with the physics-based distributed parameter catchment models due to the large number of model parameters needed to achieve calibration, the difficulty associated with calibrating the model at more than one location within the catchment, and the ability to predict multiple catchment response variables (e.g. streamflow, sediment, nitrogen and phosphorus) (White and Chaubey, 2005). Therefore, sensitivity analysis methods are needed that can accommodate a large number of parameters while considering several output variables at more than one location within the catchment. Sensitivity analysis methods reducing the number of parameters to be adjusted during calibration are important for simplifying the use of these models (van Griensven et al., 2002). These methods identify parameters that do or do not have a significant influence on the model simulations of output variables.

Currently, adoption of SWAT as a tool for predicting land use change impacts on water quality in the Yarra River catchment, Victoria (Australia) is being considered. SWAT is a promising model for long-term continuous simulation in predominantly agricultural catchments (Borah and Bera, 2003). Applications of physics-based water quality models like SWAT are limited in Australia, mainly because of data-poor environment. Information on erosion, soil properties or spatially referenced land use and water quality data is relatively sparse, complicating the development of water quality models (Letcher et al., 1999). Watson et al. (2003) used SWAT model to simulate only hydrology in Australian conditions. SWAT is a complex physicsbased distributed model with many parameters that can complicate calibration process. The model when includes multi-variable simultaneously at multi-site with multi-objective functions also introduces more complexity to the calibration process. Therefore, over-parameterization is a well-known and often described problem in such distributed model (van Griensven et al., 2006).

The objective of this paper is to perform a sensitivity analysis for multiple variables (streamflow, sediment, nitrogen and phosphorus) at three sites on a SWAT model developed in the agricultural part of Yarra River catchment, Victoria (Australia) so that the model calibration process can be simplified for water quality analysis purposes. 


\section{MATERIALS AND METHODS}

\subsection{Study Area}

The Yarra River located in Victoria, Australia is the source of Melbourne city's high quality drinking water and supports a thrive of agricultural industries. The Yarra River catchment has an area of over $4000 \mathrm{~km}^{2}$ with 21 percent natural vegetation, 57 percent agricultural and 22 percent urban land cover. The catchment has three distinct segments, namely: Upper, Middle and Lower Yarra segments based on land use activities (Figure 1). The Upper Yarra segment consists of mainly dense and extensive forested area. The Middle Yarra segment is mainly rural floodplains and valleys. The Lower Yarra segment is mainly urbanized floodplains, and has the poorest water quality. The annual rainfall of the Yarra River catchment varies from approximately 1,600 $\mathrm{mm}$ in the Upper Yarra to $600 \mathrm{~mm}$ in the Lower Yarra region (Das et al., 2011). Low flows occur from November to June.

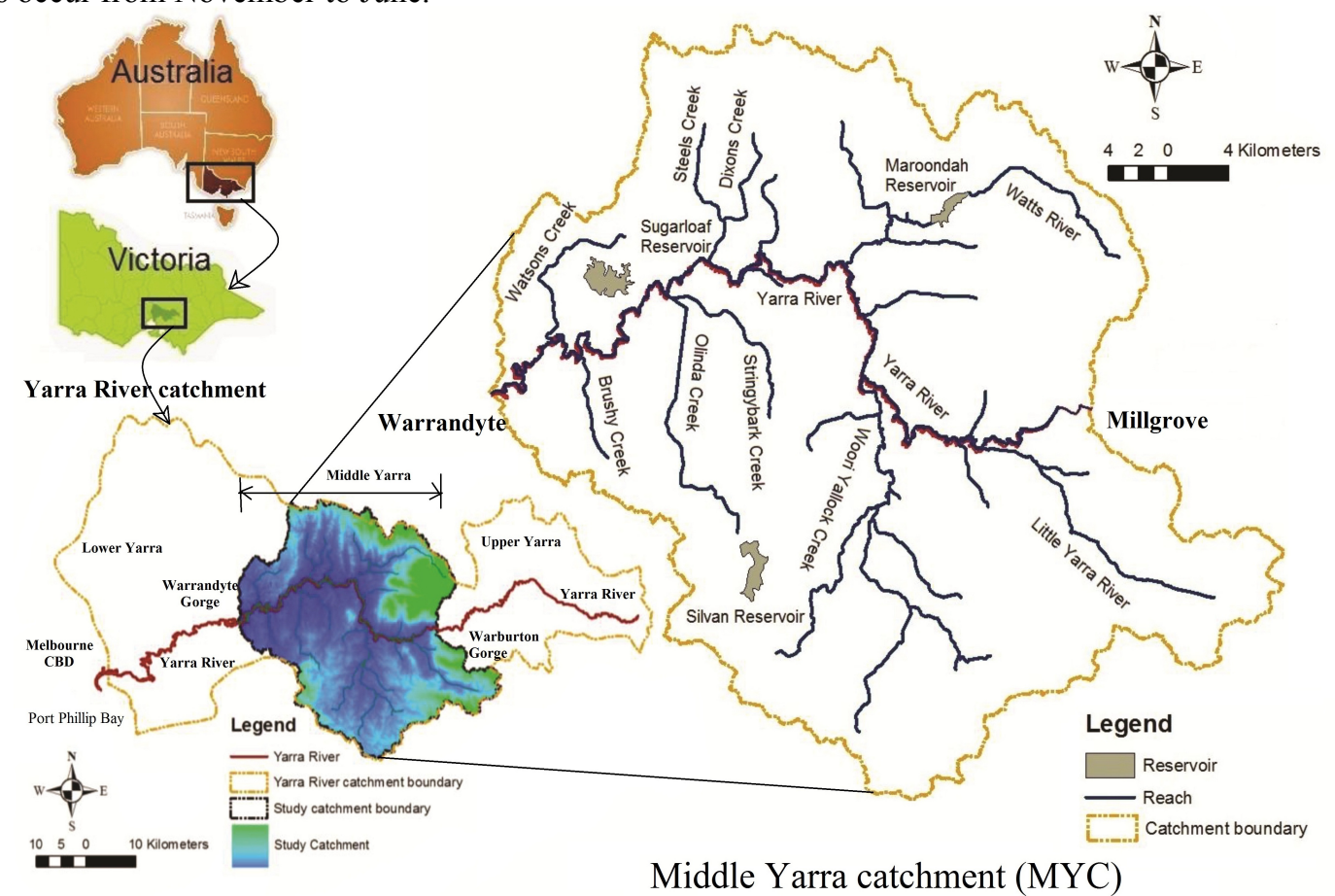

Figure 1. Location map of the Middle Yarra catchment

The Middle Yarra segment covering a total area of about $1511 \mathrm{~km}^{2}$ was selected as the case study area (Figure 1), and will be referred to as Middle Yarra Catchment (MYC) for rest of the paper. The Yarra River catchment discharges the largest amount of contaminants, both in terms of total load and load per unit area in the Port Phillip Bay region (Melbourne Water and EPA Victoria, 2009). Intensive agricultural activities from the MYC contribute a significant amount of diffuse pollutants into the river (DSE, 2006).

\subsection{SWAT Model}

This study uses the ArcSWAT interface of the SWAT2005 model (Winchell et al., 2009). The SWAT model is a non-proprietary hydrologic/water quality tool developed by the United States Department of AgricultureAgriculture Research Service (Arnold et al., 1998). It has the capability to simulate the impact of land use management on water, sediment and agricultural-chemical yields in complex catchments with varying soils, land use and management conditions over long periods of time. The ability to simulate QUAL2E based instream water quality dynamics is a definite strength of SWAT (Gassman et al., 2007).

SWAT has an embedded automatic sensitivity, and calibration and uncertainty analysis tool. The sensitivity analysis method is a combination of Latin-Hypercube and One-factor-At-a-Time (LH-OAT) sampling that allows a global sensitivity analysis for a long list of parameters with only a limited number of model runs (van Griensven et al., 2006). This method combines the robustness of the Latin Hypercube sampling that ensures that the full range of all parameters has been sampled with the precision of an OAT design assuring that the changes in the output in each model run can be unambiguously attributed to the parameter that was changed. The auto-calibration and uncertainty analysis tool ParaSol is based on the global search algorithm SCE-UA. A comprehensive review of SWAT model can be found in Gassman et al. (2007). 
Das et al., Sensitivity analysis of SWAT model in the Yarra River catchment

\subsection{Data Collection and Processing}

All necessary data types and their respective sources for the SWAT model setup and calibration are shown in Table 1. Input maps, and climate, streamflow and water quality monitoring stations are shown in Figure 2.

Table 1. Data sources for the SWAT model

\begin{tabular}{ll}
\hline Data & \multicolumn{2}{c}{ Source } \\
\hline $\begin{array}{l}\text { Digital Elevation Model } \\
\text { (DEM) }\end{array}$ & $\begin{array}{l}\text { ASTER 30m GDEM, jointly developed by The Ministry of Economy, Trade, and Industry (METI) of } \\
\text { Japan and the United States National Aeronautics and Space Administration (NASA), } \\
\text { (http://asterweb.jpl.nasa.gov/gdem-wist.asp) }\end{array}$ \\
\hline Soil & $\begin{array}{l}\text { Atlas of Australian Soils from Australian Soil Resource Information System (ASRIS) developed by } \\
\text { CSIRO and Department of Agriculture, Fisheries and Forestry (DAFF) (http://www.asris.csiro.au) }\end{array}$ \\
\hline Land use & $\begin{array}{l}\text { 50m grid raster data for the period of 1997 to May 2006 collected from Australian Bureau of } \\
\text { Agricultural and Resource Economics and Sciences (ABARES) (http://adl.brs.gov.au/landuse) }\end{array}$ \\
\hline Climate & $\begin{array}{l}\text { 16 rainfall and 4 temperature (max and min), solar radiation, wind speed and relative humidity stations } \\
\text { data from SILO climate database (http://www.longpaddock.qld.gov.au/silo) and Bureau of Meteorology } \\
\text { (BoM) (http://www.bom.gov.au/climate/data/). }\end{array}$ \\
\hline Land use management & $\begin{array}{l}\text { Manure, fertilizer type and application rate, tillage practices, cropping seasons, and irrigation rate from } \\
\text { Australian Bureau of Statistics (http://www.abs.gov.au), Department of Environment and Primary } \\
\text { Industries (http://www.depi.vic.gov.au/) and Melbourne Water (http://www.melbournewater.com.au/) }\end{array}$ \\
\hline Streamflow and water quality & $\begin{array}{l}\text { Daily streamflow and monthly water quality grab sample data collected for four sites at Warrandyte } \\
\text { (Site-3: outlet of the MYC), Healesville (Site-2), Woori Yallock (Site-1) and Millgrove (upstream inlet } \\
\text { point) as shown in Figure 2 from Melbourne Water (http://www.melbournewater.com.au/) }\end{array}$ \\
\hline
\end{tabular}

Soil classification for the Atlas of Australian Soils is based on the Factual Key. The Factual Key (Northcote, 1979) was the most widely used soil classification scheme prior to the Australian Soil Classification (ASC) (Isbell, 2002). The soil names as shown in the map (Figure 2b) are as per the ASC system with dominant Principal Profile Form (PPF) in brackets as per the Factual Key. The dominant soil types in the catchment are Sodosol (about 54\%) and Dermosol (about 35\%). The soil properties (depth of soil layer, texture, moist bulk density, available water capacity, organic carbon content, saturated hydraulic conductivity, moist soil albedo, USLE equation soil erodibility factor and soil hydrologic group) were available for 2 layers of the soil.
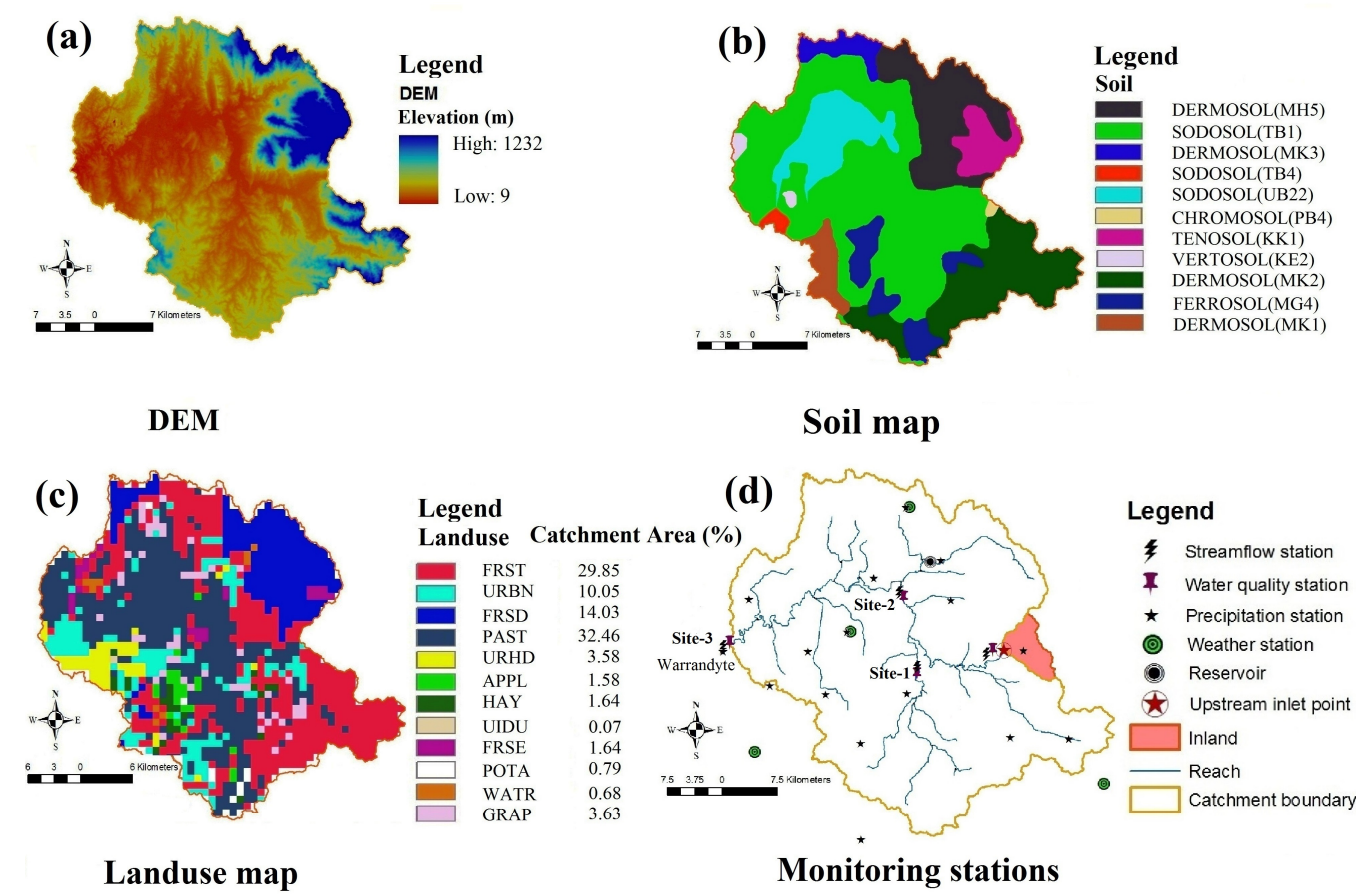

Figure 2. Spatial input maps and monitoring stations for SWAT model in the MYC

Since SWAT has pre-defined land use types through which it creates link with land use map, the land use classes generated for the MYC were re-classified and made compatible with the requirements of the SWAT model. Figure $2 \mathrm{c}$ shows the detailed land use types with pasture covering around $32 \%$ of the MYC. Climate data were collected for 1980-2008 period. Rainfall data analysis shows that there is an abrupt drop in annual average rainfall from $1140 \mathrm{~mm}(1980-1996)$ to $922 \mathrm{~mm}$ (1997-2008) indicating one of the most severe droughts in the MYC. Monthly grab sample data of Total Suspended Solid (TSS), Total Nitrogen (TN) and 
Total Phosphorus (TP) were available from the four sites (Table 1) for 1998-2008 periods along with streamflow (Q) data. The three sites as shown in Figure $2 \mathrm{~d}$ were selected for multi-site calibrations. Streamflow and water quality data were also collected from the Millgrove site to add streamflow and constituent loads from the Upper Yarra into the MYC through the "upstream inlet point" (Figure 2d) in the SWAT model. Since the correlations between concentrations of TSS, TN, TP, and streamflow (TSS: 0.650.76: TN: $0.71-0.78$, and TP: $0.58-0.76$, ) were high and statistically significant $(\mathrm{p}<0.01)$, regression model LOADEST (Runkel et al., 2004) was used to estimate constituent loads for the SWAT model calibration (Das et al., 2011). The LOADEST model performed well in estimating the constituent loads with coefficients of determination $\left(\mathrm{R}^{2}\right)$ for the regression models in LOADEST greater than 0.85 .

\subsection{SWAT Model Setup and Sensitivity Analysis}

All spatial datasets and database input files for the model were organized and assembled following the guidelines of ArcSWAT interface. The MYC was delineated into 51 sub-catchments and 431 Hydrological Response Units (HRU), which are unique combinations of land use, soil type and slope. The main methods used in modeling the hydrologic processes were curve number $(\mathrm{CN})$ method for runoff estimating, PenmanMonteith method for PET and Muskingum method for channel routing considering in-stream nutrient transformations. The model was run from 1993-2008 with a "warmup" periods of 1993-1997. SWAT has 26 streamflow, 6 sediment and 9 nutrient parameters as shown in Table 2. Each parameter has a default lower and upper boundary, and an initial value was assigned to each parameter during the model setup based on the catchment topography, soil, land use and climate. The initial values of the parameters to which model output variables are found to be sensitive, are modified during the calibration process while other parameters have been remained unchanged.

The LH-OAT sensitivity analysis was performed for Q, TN, TP and TSS variables at the three sites in the MYC for 1998-2008 periods. During the sensitivity analysis, SWAT runs $(p+1)^{*} m$ times, where $p$ is the number of parameters and $m$ is the number of LH loops (default value of $m=10$ ). For each loop, a set of parameter values is selected such that a unique area of the parameter space is sampled. This given set of parameter values was used to run a baseline simulation for the unique area. Then, using OAT, a parameter was randomly selected, and its value was changed from the previous simulation by a user-defined percentage (default value 5\%). SWAT is run on the new parameter set, and then a different parameter is randomly selected and varied. After all the parameters have been varied, the LH algorithm locates a new sampling area by changing all the parameters. Finally, the model ranked the parameters based on the objective function (Sum of the Square of the Residuals) of simulated and observed output variable monthly time series. The parameter producing the highest average percentage change in the objective function value is ranked as most sensitive. The detailed LH-OAT sensitivity analysis guidelines can be found on Van Liew and Veith (2010).

Two types of sensitivity analysis were performed to justify correlations between a parameter and multiple predicted output variables in the MYC. The first analysis considers all the variables (Q, TSS, TN and TP) and all the parameters from Table 2 simultaneously to rank the parameter sensitivity globally in the MYC where the model runs $10^{*}(41+1)=420$ times. The second analysis considers one output variable (e.g. Q), and its related parameters only at a time from Table 2 to rank the parameter sensitivity for each output variable.

\section{RESULTS AND DISCUSSION}

The global sensitivity ranks of all the parameters considering all variables (Q, TSS, TN and TP) simultaneously are shown in Table 2 . The last column in Table 2 shows the lowest rank, and is used to assess global parameter sensitivity for the MYC. Global ranks 1 are categorized as 'very important', rank 2-8 as 'important', rank 9-25 as 'slightly important' and rank 42 as 'not important' (van Griensven et al., 2006). The results for the MYC identified 4 'very important' parameters that cover channel, runoff and groundwater processes, and thus involve the hydrology of the system. In addition, there were 17 'important' parameters, 11 'slightly important' parameters and 9 parameters that did not cause any change to model output at all.

The scattered appearance of the higher ranked parameters shows that the ranking depends on the variable and the location. But, some generalizations can be made such as the overall importance of channel processes (CH_N2, SPCON, and CH_K2), groundwater processes (RCHRG_DP) and runoff processes (SURLAG, CN2 and CANMX) in the MYC. This indicates that in-stream process has significant impact on water quality along with upland processes in the MYC. These results also show that the hydrologic parameters dominate the highest parameter ranks. Some hydrologic parameters, like SURLAG, appear almost only on the pollutants list while being relatively unimportant for the streamflow (highest rank 15). This means that water quality data are potentially capable of contributing to the identification of water quantity parameters within SWAT, 
and a single parameter is correlated to multiple variables. Moreover, there are clear differences in ranking of a parameter among the three sites in the catchment. This result illustrates how parameter importance depends on land use, topography and soil types, meaning that a generalization within a catchment is limited. Hence, justify the importance of multi-site parameterization.

In general, the second type sensitivity analysis (as mentioned in Section 2.4) shows that parameter ranks of individual variable are consistent with the parameter ranks when all variables are considered simultaneously. However, ALFA_BF got comparatively higher rank for streamflow in the second analysis. Also, where CH_EROD and SOL_NO3 parameters show no sensitivity in the first analysis, were sensitive in the second analysis. Finally, 15 hydrologic parameters (ALPHA_BF, CANMX, CH_K2, CH_N2, CN2, EPCO, ESCO, GW_DELAY, GW_REVAP, GWQMN, SLOPE, SOL_AWC, SOL_K, SOL_Z, SURLAG) and 13 sediment and nutrients parameters $\left(\mathrm{CH}_{-} \mathrm{COV}, \mathrm{CH}\right.$ _EROD, NPERCO, PHOSKD, PPERCO, RCHRG_DP, SOL_LABP, SOL_NO3, SOL_ORGN, SOL_ORGP, SPCON, SPEXP, USLE_P) were considered most sensitive for the SWAT model.

Table 2. Sensitivity results for the parameters in the SWAT model for Q, TSS, TN and TP at the three sites in the MYC

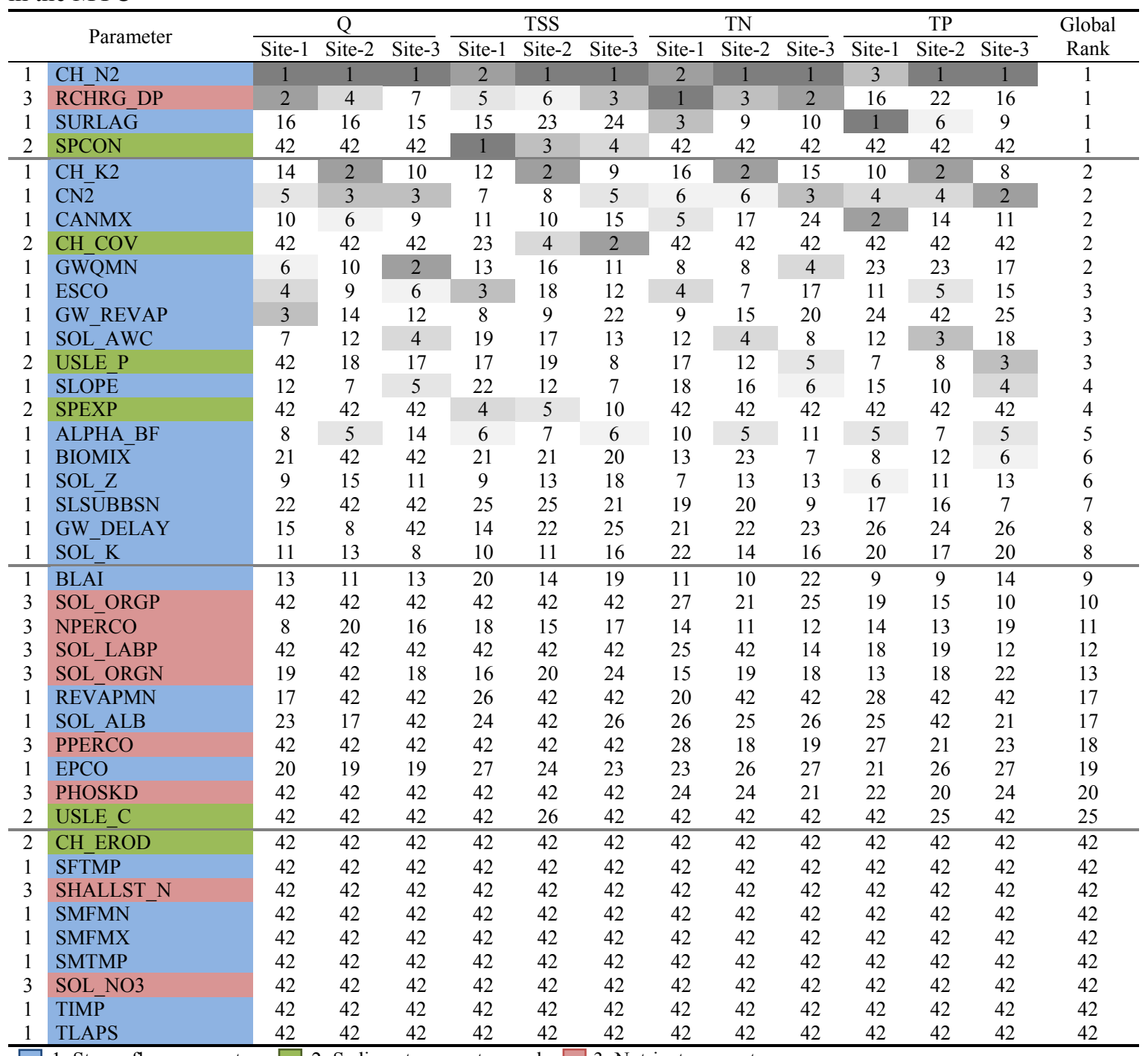

1: Streamflow parameters, $\square$ 2: Sediment parameters and $\square$ 3: Nutrient parameters

\section{CONCLUSIONS}

The setup and sensitivity analysis of SWAT model in the data-poor environment of Yarra River catchment, Victoria (Australia) is discussed in this paper. All necessary data were collected from local authorities in Australia except DEM. In general, water quality and land use management data were most sparse. The data for the SWAT model were processed with ArcGIS interface and other techniques. 
The LH-OAT sensitivity analysis provides a simple and quick way to assess parameter sensitivity for multiple variables across the MYC. 15 hydrologic parameters and 13 sediment and nutrients parameters were found most sensitive for the SWAT model. The results showed that the SWAT output variables were most sensitive to the hydrologic parameters. The results also showed that water quality variables were potentially capable of contributing to the identification of water quantity parameters within the SWAT model, and a single parameter was correlated to multiple variables. Moreover, there were clear differences in ranking of a parameter among the three sites. This result has evidenced how the parameter importance depends on land use, topography and soil types, meaning that a generalization within a catchment is limited. Hence, justify the importance of multi-site parameterization.

\section{ACKNOWLEDGMENTS}

The authors wish to thank the Australian organizations: Melbourne Water, CSIRO, DAFF, ABARES, SILO climate database, BoM, DEPI, and ABS; USDA-ARS; NASA-Japan government for data and tools.

\section{REFERENCES}

Arnold, J.G., Srinivasan, R., Muttiah, R.S., and Williams, J.R. (1998). Large area hydrologic modeling and assessment part I: model development. Journal of the American Water Resources Association, 34(1), 7389.

Borah, D.K., and Bera, M. (2003). Watershed-scale hydrologic and nonpoint-source pollution models: review of mathematical bases. Transactions of the ASAE, 46(6), 1553-1566.

Das, S.K., Ng, A.W.M., and Perera, B.J.C. (2011). Assessment of nutrient and sediment loads in the Yarra River catchment, In F. Chan, D. Marinova and R.S. Anderssen (eds), 19th International Congress on Modelling and Simulation (MODSIM), Perth, Australia, pp. 3490-3496.

DSE (2006), Strengthening the Management of the Yarra and Maribyrnong Rivers: A Background Report for Future Water Quality Management, Department of Sustainability and Environment, Melbourne.

Gassman, P.W., Reyes, M.R., Green, C.H., and Arnold, J.G. (2007). The Soil and Water Assessment Tool: historical development, applications, and future research directions. Transactions of the ASABE, 50(4), 1211-1250.

Green, C.H., and Van Griensven, A. (2008). Autocalibration in hydrologic modeling: Using SWAT2005 in small-scale watersheds. Environmental Modelling \& Software, 23(4), 422-434.

Isbell R. (2002). The Australian Soil Classification, Revised edn, CSIRO, Melbourne, Australia.

Letcher, R.A., Jakeman, A.J., Merritt, W.S., McKee, L.J., Eyre, B.D., and Baginska, B. (1999). Review of Techniques to Estimate Catchment Exports, NSW Environmental Protection Authority.

Melbourne Water and EPA Victoria (2009). Better Bays and Waterways - A Water Quality Improvement Plan for the Port Phillip and Westernport Region, Melbourne, Australia.

Northcote, K.H. (1979). A Factual Key for the Recognition of Australian Soils, 4th edn, Rellim Technical Publishers, Glenside, SA.

Runkel, R.L. Crawford, C.G., and Cohn, T.A. (2004). Load Estimator (LOADEST): A FORTRAN program for estimating constituent loads in streams and rivers. In: Techniques and Methods Book 4, Chapter 5, pp.69. US Department of the Interior, US Geological Survey, Reston, Virginia.

Sharpley, A.N. (1995). Dependence of runoff phosphorus on extractable soil phosphorus. Journal of Environmental Quality, 24(5), 920-926.

Sims, J.T., Simard, R.R., and Joern, B.C. (1998). Phosphorus loss in agricultural drainage: Historical perspective and current research. Journal of Environmental Quality, 27(2), 277-293.

van Griensven, A., Francos, A., and Bauwens, W. (2002). Sensitivity analysis and auto-calibration of an integral dynamic model for river water quality. Water Science and Technology, 45(9), 325-332.

van Griensven, A., Meixner, T., Grunwald, S., Bishop, T., Diluzio, M., and Srinivasan, R. (2006). A global sensitivity analysis tool for the parameters of multi-variable catchment models. Journal of Hydrology, 324(1-4), 10-23.

Van Liew, M.W. and Veith, T.L. (2010), Guidelines for using sensitivity analysis and auto-calibration tools for multi-gage or multi-step calibration in SWAT.

Watson, B., Ghafouri, M., and Selvalingam, S. (2003). Application of SWAT to model the water balance of the Woady Yaloak River catchment, Australia, In R. Srinivasan, J. Jacobs and R. Jensen (eds), SWAT 2003: 2nd International SWAT Conference, Temple, Texas, pp. 94-110.

White, K.L., and Chaubey, I. (2005). Sensitivity analysis, calibration, and validations for a multisite and multivariable SWAT model, Journal of the American Water Resources Association, 41(5), 1077-89.

Winchell, M., Srinivasan, R., Di Luzio, M., and Arnold, J.G. (2009). ArcSWAT 2.3.4 Interface for SWAT2005, User's Guide, Grassland, Soil and Water Research Laboratory, Temple, TX. 